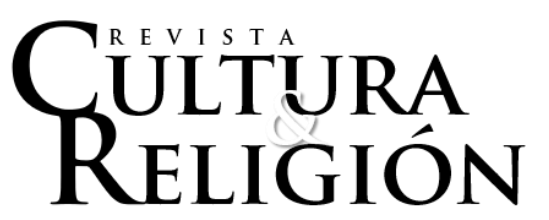

Vol. XIII, N² (2019) pp. 75-102

Recibido: 21 de noviembre, 2018.

Aceptado: 27 de julio, 2019.

\title{
DIVERSIDADE CULTURAL COMO SECULARIZAÇÃO? EXAME DA CORRELAÇÃO ENTRE OS ÍNDICES DE RELIGIOSIDADE E DIVERSIDADE NA EUROPA DO SÉCULO XXI ${ }^{1}$
}

\section{Cultural diversity as secularization? Analysis of the correlation between religiosity and diversity indexes in 21st-century Europe}

\author{
por \\ Jorge Botelho Moniz** \\ Universidade Nova de Lisboa \\ jorgemoniz.fellow@gmail.com
}

\begin{abstract}
Resumo
A rápida globalização da segunda metade do século XX e o advento de novas tendências demográficas e migratórias despertaram o interesse das ciências sociais para a crescente complexificação das dinâmicas culturais regionais. Os cientistas sociais começaram a associar a diversidade cultural à modernidade, vaticinando-a como uma condição incontornável e perene das sociedades hodiernas que tem efeitos nos e é afetada pelos fenómenos religiosos. Contudo, pouco exames empíricos sistemáticos e aprofundados foram feitos para aferir a validade dessa proposição. Com este trabalho, propomos a criação de um índice de diversidade, baseado em quatro dimensões - linguística, étnica, religiosa e local de nascimento -, que seja correlacionável com uma medida de religiosidade individual. Concluímos que, para o conjunto de países europeus selecionados e para o período temporal analisado (1999-2014), a teoria que assevera que a diversidade cultural apenas provoca a deslocação e recomposição do religioso e não o seu declínio não tem validade empírica.
\end{abstract}

Palavras-chave: secularização, diversidade cultural, índice, religiosidade, Europa.

\footnotetext{
${ }^{1} \mathrm{O}$ artigo faz parte do projeto de investigação "Secularization theories in Europe: New qualitative na quantitative outlooks on contemporary religious phenomena", apoiado pela FCT - Fundação para a Ciência e a Tecnologia (Portugal) (Referência/SFRH/BD/107762/2015).

* Doutor em Ciência Política e Investigador associado ao IPRI - Instituto Português de Relações Internacionais da Universidade Nova de Lisboa e ao CITER - Centro de Investigação em Teologia e Estudos de Religião da Universidade Católica Portuguesa. https://orcid.org/0000-0002-1782-8037
}

\section{Revista Cultura \& Religión Vol. XIII, 2019 № 2 (julio-diciembre)}

Cómo citar este artículo: Botelho, J. (2019). "Diversidade cultural como secularização? Exame da correlação entre os índices de religiosidade e diversidade na Europa do século XXI”. Revista Cultura \& Religión.13(2). pp.75-102. 


\begin{abstract}
The fast globalization of the second half of the 20th century and the advent of new demographic and migratory trends have awaken social sciences to the growing complexity of regional cultural dynamics. Social scientists have begun to associate cultural diversity with modernity, predicting it as an inescapable and perennial condition of modern societies that has effects on and that is affected by religious phenomena. However, few systematic and indepth empirical researches have been made to assess these assertions. Thus, our paper puts forward the formulation of a diversity index (independent variable) based on four dimensions - linguistic, ethnic, religious, and birthplace - that is correlated with a (dependent) variable of individual religiosity. We conclude that, for the set of European countries and for the time period under analysis (1999-2014), the theory of cultural diversity that states that more diversity only causes the displacement and recomposition of religiosity has no empirical validity.
\end{abstract}

Keywords: secularization, cultural diversity, index, religiosity, Europe.

\title{
Introdução
}

Nos últimos decénios, as discussões académicas sobre religião têm sido caracterizadas por um confronto teórico entre duas narrativas sobrepostas, embora aparentemente opostas. Por um lado, a conceção de uma perda de relevância social da religião, preconizada pelos defensores das teorias da secularização, na maioria cientistas sociais europeus. Por outro lado, a ideia do regresso (do significado social) das religiões, maioritariamente defendido por teóricos estadunidenses.

No entanto, segundo Casanova (2007, p.3), chegou-se a um "ponto morto neste debate", pois a teoria tradicional da secularização adequa-se, relativamente bem, à realidade europeia, mas não à norte-americana, enquanto a narrativa da vitalidade dos mercados religiosos (desregulados) é relativamente eficaz para explicar a realidade dos Estados Unidos da América, mas não a da Europa. Os teóricos afirmam ser necessária uma mudança de rumo das pesquisas sobre esse fenómeno (Halikiopoulou, 2011), porque, chegados a este "beco sem saída para o estudo sociocientífico da religião" (Wohlrab-Sahr e Burchardt, 2017, p.144), o debate sobre a secularização tem-se tornado "infrutuoso" (Casanova, 2007, p.1, 3).

No geral, concordamos com essas proposições. Contudo, relembramos que, com a integração, aplicação e desenvolvimento da ideia das múltiplas modernidades de Shmuel Eisenstadt no debate sobre a secularização, surgiram uma série de inovações conceptuais e epistemológicas sobre o lugar do religioso no mundo. Em especial, as ideias de dessecularização, pós-secularização, múltiplas secularizações ou secularidades e secularização contextual. O problema desta miríade de inovações ou renovações teóricas e conceptuais é que, segundo Pickel (2017), mantêm em suspenso uma questão que ainda não

Revista Cultura \& Religión Vol. XIII, 2019 N² 2 (julio-diciembre)

Cómo citar este artículo: Botelho, J. (2019). "Diversidade cultural como secularização? Exame da correlação entre os índices de religiosidade e diversidade na Europa do século XXI”. Revista Cultura \& Religión.13(2). pp.75-102. 
foi decidida definitivamente. Isto é, que processos da modernidade, se é que algum, conseguem descrever as atuais mutações ou deslocações do religioso nas sociedades contemporâneas? Efetivamente, a maioria dessas conceptualizações mais recentes é sustentada cientificamente pela análise de fatores históricos, pelas reflexões de cariz sociológico e/ou filosófico ou pela descrição de fenómenos sociopolíticos. Raros têm sido os estudos que associam a dimensão teórica a uma dimensão mais empírica - estatística - que analise com rigor os desenvolvimentos (positivos ou negativos) dos fenómenos religiosos. Mesmo nos casos em que isso sucedeu (Norris e Inglehart, 2004; Pickel, 2017) os estudos foram baseados, não raras vezes, em variáveis uni ou bidimensionais, negligenciando a sistematização das várias teorias da secularização e das suas alternativas teóricas para compreender e interpretar os fenómenos de deslocação, revitalização ou declínio do religioso nas sociedades contemporâneas.

Para Vilaça, Sell e Moniz (2017), na análise dos fenômenos religiosos contemporâneos, são cada vez mais necessárias novas grades analíticas: nova economia, mass media digitais ou migrações estão entre as forças nucleares. Peter Berger (2014), que desde a década de 1990 vem revendo seu tópico original, entende o pluralismo, e não a secularização, como o tema central na sociologia da religião. Também Maria das Dores Machado (2007) considera que a força globalizante destes fenômenos tem efeitos nas expressões religiosas contemporâneas e que estes instigam os investigadores sociais a estudar as tendências de heterogeneidade cultural das sociedades hodiernas. Finalmente, Vilaça $e t$ al. (2014) acreditam que, na tentativa de compreender a religião nas sociedades hodiernas, o foco dos investigadores deve estar nos fenómenos migratórios e nas mudanças que, diferentes tradicões religiosas e diferentes arranjos Estado-religiões, provocam na alma das distintas sociedades. A mobilidade geográfica e o consequente transnacionalismo cultural (étnico, linguístico ou religioso) desenham um cenário social progressivamente mais diverso e que tem impactos em muitos aspectos da vida cultural e social. Isso é particularmente evidente no mundo Atlântico Norte onde o paradigma de migração mudou abruptamente: sociedades tipicamente de emigração tornaram-se, sobretudo nas últimas décadas, sociedades de imigração ou de migração global.

Nesse sentido, o nosso trabalho foca-se na teoria da diversidade ${ }^{2}$ cultural, não só porque a consideramos uma das teorias nucleares da secularização - concomitantemente com

\footnotetext{
${ }^{2}$ Como sugere a literatura especializada (Beckford, 2003; Vilaça, 2006; Berger, 2014), deve-se fazer uma distinção clara entre os conceitos de pluralismo e diversidade e optar, fundamentadamente, por um deles. O âmago do seu argumento é que o pluralismo é um conceito normativo, enquanto a diversidade é um termo descritivo. O primeiro, como denuncia o sufixo ismo, é um sistema de valores, instituições ou processos que aceita a diversidade como um valor positivo; o segundo diz respeito, descritiva, empírica e factualmente, ao grau de heterogeneidade cultural existente numa determinada sociedade ou num mesmo contexto social. Neste trabalho, pelo foco estar na análise do nível de heterogeneidade das sociedades, optamos explicitamente pelo último.
}

Revista Cultura \& Religión Vol. XIII, 2019 N² 2 (julio-diciembre)

Cómo citar este artículo: Botelho, J. (2019). "Diversidade cultural como secularização? Exame da correlação entre os índices de religiosidade e diversidade na Europa do século XXI”. Revista Cultura \& Religión.13(2). pp.75-102. 
as suas sub-teorias clássicas da racionalização, societalização e diferenciação funcional e com a sua versão mais moderna da segurança existencial -, mas também porque é atualmente apontada como um dos fatores-chave mais consensuais da modernização que explica a diminuição do significado microssocial da religião. Por conta da evolução e centralidade deste debate, consideramos necessária a condensação dos seus argumentos teóricos em variáveis empíricas mensuráveis que, além disso, possam ser correlacionadas com níveis multidimensionais e abrangentes de religiosidade. $\mathrm{O}$ reconhecimento destas novas grades analíticas e o emprego de uma metodologia mais empirista, mas com suporte teórico, podernos-á aproximar do nosso objetivo principal - responder à supracitada interrogação de Pickel e compreender se as teorias da secularização são relevantes para interpretar e descrever as mutações do religioso, sobretudo, ao nível micro (individual). Assim sendo, adotamos uma metodologia hipotético-dedutiva, procedendo a análises qualitativas e quantitativas que nos permitem pôr à prova os pressupostos internos da teoria da secularização sobre a diversidade cultural. Para cumprir este desiderato, criamos um índice de diversidade cultural (a nossa variável independente), baseado em quatro dimensões de heterogeneidade - linguística, étnica, religiosa e local de nascimento -, que é correlacionável com uma medida de religiosidade individual, o índice de religiosidade (a variável dependente). Isso ajudar-nos-á a perceber a validade e atualidade da teoria da diversidade cultural e descrever de forma mais precisa os atuais movimentos do fenentos religioso no conjunto de países europeus selecionado.

\section{Sobre a diversidade cultural}

O termo diversidade tem a sua etimologia no latim diversitas, procurando dizer variedade ou diferença. É a representação, num determinado sistema social, da multiplicidade de diferenças e similaridades que existem entre os indivíduos ou os grupos que os representam. É a qualidade do diverso (dimensão positiva), por oposição à cultura de grupo, à homogeneização de culturas ou à monocultura (dimensão negativa). A noção de diversidade está, portanto, associada aos conceitos de pluralidade, multiplicidade ou heterogeneidade, dizendo respeito à miríade de ideias, características ou elementos distintos que distinguem os indivíduos sobre um determinado assunto, contexto ou ambiente. É, nas palavras de Crystal (2002, p.33), uma expressão "incorrigivelmente plural” e, acrescentaríamos nós, incontornavelmente associada à multiplicidade de identificações culturais de cada grupo social.

Com efeito, a diversidade que queremos analisar é a cultural ${ }^{3}$, pois é a cultura através da sua capacidade de inserção e adequação do ser ao meio - que explica, dá sentido e agrega as diferentes cosmologias sociais, como as étnicas, religiosas ou linguísticas. Não

\footnotetext{
${ }^{3}$ Doravante, sempre que nos referirmos ao termo diversidade, estaremos a fazê-lo à luz da ideia de diversidade cultural. Salvo quando indicarmos o contrário.
}

Revista Cultura \& Religión Vol. XIII, 2019 № 2 (julio-diciembre)

Cómo citar este artículo: Botelho, J. (2019). "Diversidade cultural como secularização? Exame da correlação entre os índices de religiosidade e diversidade na Europa do século XXI”. Revista Cultura \& Religión.13(2). pp.75-102. 
surpreende que, ao tratarem do tópico da diversidade, os cientistas sociais normalmente o associem à cultura (Ottaviano e Peri, 2006; Patsiurko, Campbell e Hall, 2012; Dohse e Gold, 2013).

Embora a diversidade não seja um fenómeno propriamente recente (Taylor, 2007; Berger, 2014), com a acelerada globalização da segunda metade do século XX tornou-se, segundo Taylor (2007, p.437), irreconhecível para e incomparável com qualquer época histórica anterior. O mundo contemporâneo tem-se tornado gradualmente mais heterogéneo cultural, religiosa e etnicamente, sendo marcado por uma diversidade inédita de cosmovisões que se multiplicam irrefreavelmente (Taylor, 2007).

Esta é, de acordo com o estado da arte, uma marca indelével da modernização. Para Berger (2014, p.53), a modernidade e a diversidade estão inelutavelmente cruzadas. A primeira leva "necessariamente" à segunda, porquanto liberta todos os processos que a estimulam, nomeadamente a urbanização, as migrações em massa, a alfabetização e o desenvolvimento das tecnologias de comunicação ${ }^{4}$. Também para Vilaça $(2006$, p.22) a diversidade tornou-se num dos "traços da modernidade". Por causa do aumento dos fluxos migratórios e da mobilidade geográfica e do progresso dos mass media as sociedades diversificam-se cultural, étnica, religiosa e linguisticamente. Todavia, esta crescente heterogeneidade não é passageira. De acordo com Vilaça (2006, p.22), ela é a nova "norma e não uma mera situação transitória". Estas perspetivas são corroboradas por outros autores. Martin (2005, p.157) diz que o pluralismo é uma característica "presente de forma massiva no mundo contemporâneo", Taylor (2007, p.300) chama-lhe "supernova" da era moderna, marcada por um "pluralismo galopante", Pickel (2017, p.290) diz que é um dos "prognósticos seguros para a Europa" e Vilaça et al. (2014, p.2) preveem que o seu crescimento se manterá como resultado dos efeitos da globalização.

Por conta dos seus desenvolvimentos globais, o tema da diversidade tornou-se numa das mais "promissoras agendas de pesquisa" (Pollack, 2014, p.115), sendo um dos "tópicos mais importantes" nas ciências sociais contemporâneas (Doktór, 2009, p.26). Para isto muito ajudou o facto de os teóricos da secularização terem começado a associá-la aos efeitos da modernidade. O seu argumento básico é o seguinte: a modernidade não leva necessariamente à secularização; porém, conduz inevitavelmente à diversidade (Berger, Davie e Fokas, 2008; Berger, 2014; Vilaça et al. 2014).

Nas últimas décadas, muitos têm procurado desenvolver metodologias para compreender este fenómeno. Johnson e Grim (2013) determinam dois tipos de diversidade: interna e exterior; Gardenswartz e Rowe (2003) falam em quatro camadas da diversidade; o

\footnotetext{
${ }^{4}$ Esta é uma revisão relativamente ao argumento original de Berger (1990 [1967]). Na década de 1960, o autor considerava, inversamente, que a secularização, por conta da desmonopolização das tradições religiosas, levava a uma situação de diversidade e não o contrário.
}

\section{Revista Cultura \& Religión Vol. XIII, 2019 N² 2 (julio-diciembre)}

Cómo citar este artículo: Botelho, J. (2019). "Diversidade cultural como secularização? Exame da correlação entre os índices de religiosidade e diversidade na Europa do século XXI”. Revista Cultura \& Religión.13(2). pp.75-102. 
Pew (2014) também refere que as ciências sociais definiram quatro formas de diversidade; e Beckford (2003) vai ainda mais longe, afirmando que a diversidade deve ser distinguida, analiticamente, através de cinco significados. Todavia, não há propriamente uma uniformidade no tratamento da questão da diversidade, à exceção da ideia geral de que, à semelhança de tantos outros, é um conceito multidimensional e que pode ser medido de várias formas. No entanto, a literatura especializada na área tem, implicitamente, chegado a um consenso sobre a melhor forma de analisar, subdividir e quantificar a diversidade. Em particular, desde os inícios do século XXI que têm surgido estudos sobre a fracionalização (Alesina et al. 2003; Fearon, 2003; Patsiurko, Campbell e Hall, 2012) e que pretendem descrever, medir e entender os efeitos da diversidade, estes autores chamar-lhe-ão heterogeneidade, da e na população.

A fracionalização, ou seja, o grau de divisão (de alguém ou algo) em diferentes grupos ou partes, dentro duma determinada sociedade ou região, é tipicamente medido através das seguintes três dimensões: a étnica, a linguística e a religiosa.

A fracionalização étnica ou a etnicidade é, do conjunto, para Alesina et al. (2003, p.6), a "principal variável" de análise. Associada, anteriormente, à dimensão linguística - a heterogeneidade etnolinguística - , a etnicidade passou a ser considerada autonomamente. Isto levou os teóricos a afastar-se de definições padronizadas de etnia ou grupo étnico que normalmente incluíam a língua e a religião e que se baseavam na ideia duma crença comum numa ancestralidade e/ou em características culturais (reais ou presumidas) partilhadas. Apesar do pouco desenvolvimento teórico neste campo, a diversidade étnica aqui mencionada é concernente ao conjunto de características biológicas, como a origem racial ou a cor da pele dos indivíduos (Alesina et al., 2003; Patsiurko, Campbell e Hall, 2012).

A fracionalização linguística passou a ser tratada, como vimos, como uma dimensão de análise independente da diversidade étnica. Para Alesina et al. (2003, p.5), a separação entre a língua e as características raciais ou físicas dos indivíduos é uma "melhoria" relativamente às pesquisas anteriores. A questão linguística é, para os autores, tão ou mais relevante do que a diversidade étnica. Não considerar a linguagem como fator de diversidade é, na linha de Crystal (2002, p.34), um "erro", porquanto a língua é parte integrante da identidade dos indivíduos. Fearon (2003), aliás, constrói a sua medida de fracionalização cultural, baseando-se apenas no grau de similaridade ou distância entre línguas. Este tipo de fracionalização é então medido com referência à percentagem de falantes da língua nativa duma determinada sociedade (Alesina et al., 2003; Patsiurko, Campbell e Hall, 2012).

A fracionalização religiosa é, de acordo com Alesina et al. (2003, p.6), provavelmente a dimensão da fracionalização "menos controversa e arbitrária", pois as fronteiras da religião são mais claras e consistentes entre países. Não obstante, alguns autores, como Fearon (2003), deixem a dimensão religiosa propositadamente de fora, outros autores continuam a

Revista Cultura \& Religión Vol. XIII, 2019 N² 2 (julio-diciembre)

Cómo citar este artículo: Botelho, J. (2019). "Diversidade cultural como secularização? Exame da correlação entre os índices de religiosidade e diversidade na Europa do século XXI”. Revista Cultura \& Religión.13(2). pp.75-102. 
considerá-la nos seus trabalhos, medindo-a, sobretudo, através dos dados disponíveis sobre afiliação religiosa e sobre a distribuição dos grupos religiosos (Alesina et al., 2003; Patsiurko, Campbell e Hall, 2012).

Estas três medidas são entendidas como a tríade de "aspetos principais da diversidade cultural" (Alesina et al., 2003) que melhor "capta as [suas] distinções" (Patsiurko,_Campbell \& Hall, 2012). Com efeito, elas têm recebido uma grande aceitação e adesão dos cientistas sociais, mas não só, que têm como fito estudar os efeitos da diversidade cultural no desempenho da economia (Patsiurko, Campbell e Hall, 2012), nos conflitos políticos e sociais, na fragilidade dos Estados (Alemu, 2016) ou nos valores familiares.

Mais recentemente vem-se falando da necessidade de, para se compreender inteiramente o fenómeno da diversidade, se adicionarem outros fatores além do étnico, linguístico e religioso (Dohse e Gold, 2013; Alemu, 2016). Os teóricos vêm defendendo a ampliação do conceito de diversidade cultural por meio da integração de uma dimensão que considere o local de nascimento dos indivíduos (Ottaviano e Peri, 2006; Dohse e Gold, 2013; Alesina, Harnoss e Rapoport, 2016). Isto é particularmente relevante, porque a medida local de nascimento, contrariamente à etnicidade, língua ou religião, penetra nas diferentes experiências de vida dos indivíduos, nas suas diferenças formativas e educacionais e no desenvolvimento de perspetivas distintas. Assim sendo, segundo Alesina, Harnoss e Rapoport (2016), a diversidade do local de nascimento difere, conceptualmente, das outras três medidas de diversidade citadas, mas também se distingue empiricamente, pela forte falta de correlação entre a primeira e as segundas. A dimensão local de nascimento parte do pressuposto de que a cultura nativa é homogénea e que, por conseguinte, a diversidade cultural é determinada pela proporção de população não-nativa que vive nessa região. Por um lado, observa o tamanho (da população nascida no estrangeiro); por outro lado, a multiplicidade (dos não nativos). Ou seja, esta medida de diversidade intercultural (Dohse e Gold, 2013, p.7-8) ou diversidade populacional (Alesina, Harnoss e Rapoport, 2016) deduz a diversidade cultural duma região por meio da distinção entre população nativa e estrangeira, mas também através da variedade da última.

De acordo com Erikson e Jonnson (1999), a definição de indicadores para as quatro dimensões ora citadas - etnicidade, língua materna, confissão religiosa e país de origem deve dar elementos suficientes para a construção dum índice de diversidade cultural bastante preciso. Por conta desta alegada precisão, o ESS definiu-as como as dimensões nucleares para a compreensão dum conceito amplo de identidade étnica.

\section{Proposta de composição e medição do índice de diversidade cultural}

A necessidade de determinar certas dimensões da diversidade que permitissem a construção de índices e, por consequência, o estudo dos efeitos da diversidade nas sociedades

Revista Cultura \& Religión Vol. XIII, 2019 № 2 (julio-diciembre)

Cómo citar este artículo: Botelho, J. (2019). "Diversidade cultural como secularização? Exame da correlação entre os índices de religiosidade e diversidade na Europa do século XXI”. Revista Cultura \& Religión.13(2). pp.75-102. 
não é nova. Desde os meados da década de 1990 que vários estudos têm investigado este assunto, nomeadamente no campo da economia. Como nos dizem Dohse e Gold (2013, p.6), no geral, a atual literatura sobre os efeitos da diversidade cultural é "ainda inconclusiva". Por um lado, vem-se reconhecendo a correlação positiva entre a diversidade cultural e a inovação e o empreendedorismo. Contudo, esta correlação é normalmente restringida ao espaço europeu, nomeadamente ao mais rico, e à imigração qualificada aí existente. Por outro lado, ainda vem sendo difícil documentar os efeitos positivos globais da diversidade (Ottaviano e Peri, 2006). Com efeito, salvo algumas exceções (Alesina, Harnoss e Rapoport, 2016), os estudos apontam frequentemente para uma correlação negativa entre diversidade cultural e instituições e políticas públicas, oferta de bens públicos ou crescimento económico (Alesina et al., 2003; Patsiurko, Campbell e Hall, 2012).

De facto, foram construídas muitas medidas de quantificação da diversidade, como os índices de fracionalização (Alesina et al., 2003; Patsiurko, Campbell e Hall, 2012), diversidade cultural (Fearon, 2003), diversidade populacional (Alesina, Harnoss e Rapoport, 2016) e até mesmo um de diversidade religiosa (Johnson e Grim, 2013). Também foram adotadas muitas fórmulas para a sua construção.

A mais usada, mas também mais criticada (por ser determinada pela percentagem do grupo dominante), é a Herfindahl-Hirschman, sobre a concentração do mercado. Complementarmente tem-se recorrido ao índice de Theil sobre a diversidade cultural, de modo a medir-se, com maior amplitude, a percentagem e a variedade de culturas existentes numa certa sociedade ou região.

Não obstante o refinamento teórico e metodológico em torno dos efeitos da diversidade nas várias esferas da vida social, os autores parecem negligenciar a questão religiosa. Como pudemos atestar e tanto quanto sabemos, não existem estudos que correlacionem a diversidade cultural com a religiosidade. Os estudos que fazem esta aproximação, como Voas, Olson e Crockett (2002), Norris e Inglehart (2004), Doktór (2009) ou os da escola da economia religiosa ${ }^{5}$, fazem-nos à luz do conceito de pluralismo (no caso, religioso). Ou seja, ainda que queiram analisar os efeitos da heterogeneidade dos grupos sociais na vitalidade religiosa, fazem-no, normalmente, através da perspetiva conceptual errada. Além disso, não raras vezes, recorrem a medidas uni ou bidimensionais, associando o pluralismo, por exemplo, apenas ao grau de aceitação de vizinhos com credos diferentes.

Não obstante o nosso impulso inicial de utilizar os índices de fracionalização supracitados, a verdade é que não o pudemos fazer por conta do substancial desfasamento

\footnotetext{
${ }^{5}$ A teoria da economia religiosa, defendida por autores como Laurence Iannaccone, Rodney Stark, Roger Finke, Stephen Warner ou William Bainbridge, diz essencialmente que nas sociedades modernas existe uma procura social permanente por religião, mas que a vitalidade religiosa depende da diversidade de e competição entre firmas religiosas (igrejas ou seitas) em atividade no mercado.
}

Revista Cultura \& Religión Vol. XIII, 2019 № 2 (julio-diciembre)

Cómo citar este artículo: Botelho, J. (2019). "Diversidade cultural como secularização? Exame da correlação entre os índices de religiosidade e diversidade na Europa do século XXI”. Revista Cultura \& Religión.13(2). pp.75-102. 
entre o nosso período temporal de análise (1999-2014) ${ }^{6}$ e aquele que serviu de referência à fracionalização. Por exemplo, os dados de Alesina et al. (2003) para a etnicidade cobrem o período 1979-2001 (apenas cobrindo os nossos três primeiros de análise ${ }^{7}$ ) e os de Fearon (2003) reportam-se à década de 1990. Até mesmo os trabalhos mais recentes, como os de Patsiurko, Campbell e Hall (2012) ou de Gören (2014) não são pertinentes para correlacionar com a nossa variável dependente. Os dos primeiros vão de 1985 até 2000 e os do segundo de 1960 a 1999.

Assim sendo, tivemos de construir de raiz o nosso índice de diversidade, mas inspirando-nos nos indicadores e fontes citadas pelos autores. Recorremos, nomeadamente para a edificação das dimensões diversidade religiosa e local de nascimento, aos bancos de dados seguintes: WCD - World Christian Databease, ESS - European Social Survey, OCDE - Organisation for Economic Co-operation and Development. Em particular, as duas primeiras são comummente usadas em estudos de autores que trabalham com o fenómeno religioso, nomeadamente na Europa, sendo reconhecidas pela qualidade e pelo rigor dos seus bancos de dados. Nas dimensões diversidade étnica e linguística socorremo-nos, sobretudo, dos dados atualizados da Encyclopadia Britannica e do Ethnologue: Languages of the World, respetivamente.

Estas bases de dados são centrais nos trabalhos dos teóricos da fracionalização. A primeira é uma enciclopédia generalista, publicada desde meados do século XVIII, e que disponibiliza dados sobre a composição étnica, através da distribuição da percentagem dos grupos étnicos, para a maioria dos países do mundo. Pelo facto de os seus dados serem, como explicaremos adiante, imperfeitos, decidimos complementá-los com outras fontes como o World Directory of Minorities and Indigenous Peoples baseado nos dados do ACNUR - Alto Comissariado das Nações Unidas para os Refugiados ou do Eurobarómetro da Comissão Europeia. A segunda, publicada pela Sociedade Internacional de Linguística - SIL International, oferece, desde 1951, um catálogo sobre as línguas do mundo. É uma referência, porque contém, por exemplo, na sua vigésima edição (2017), uma base de dados com mais de 7.000 línguas (escritas ou faladas), incluindo informação sobre os falantes, a localização, os dialetos ou a afiliação linguística. O Ethonologue serve de base para a construção de índices de diversidade linguística, como aquele ao qual recorremos e que foi publicado num relatório da UNESCO sobre diversidade cultural e diálogo intercultural (2005).

\footnotetext{
${ }^{6}$ A escolha destas datas não é casual. Com efeito a sua escolha deve-se ao fato de as formas mais modernas (individualizadas e indeterminadas) de religião e a diversidade das suas expressões só terem sido estudadas, pelas ciências sociais de forma mais sistemática, nas últimas década do século XX. Ou seja, se só a partir desse período os investigadores mostraram maior sensibilidade para a difusão e diversidade das expressões religiosas modernas, isso significa que, até então, os dados estatísticos disponíveis dificilmente contemplariam dimensões da religiosidade individual que se pudessem contrapor a variáveis independentes como a diversidade cultural. ${ }^{7}$ Especificamente, para a análise dos países selecionados, estes dados não cobrem o nosso período de análise. Para a Itália, os dados disponíveis são de 1983, Espanha 1991, Eslováquia 1996 e Áustria, Polónia e Portugal 1998.
}

\section{Revista Cultura \& Religión Vol. XIII, 2019 Nº 2 (julio-diciembre)}

Cómo citar este artículo: Botelho, J. (2019). "Diversidade cultural como secularização? Exame da correlação entre os índices de religiosidade e diversidade na Europa do século XXI”. Revista Cultura \& Religión.13(2). pp.75-102. 
Posto isto, elenquemos as nossas dimensões da diversidade cultural e os indicadores que as compõem:

1. Diversidade linguística:

- Língua mais frequentemente falada em casa: a primeira mencionada (fonte: ESS).

- Número de línguas vivas (fonte: Ethnologue).

- Número de línguas vivas imigrantes (\% do total das línguas vivas) (fonte: Ethnologue).

- Cobertura territorial da língua nativa (fonte: Ethnologue).

- Índice de diversidade linguística (fonte: UNESCO).

2. Diversidade étnica:

- Pertence a um grupo étnico minoritário no país? (Fonte: ESS).

- Grupo de maioria étnica (nativa) (\% do total) (fonte: Encyclopædia Britannica).

- Grupo de maioria étnica (nativa) (\% do total) (fonte: World Directory of Minorities and Indigenous Peoples).

- Número de etnias percentualmente relevantes (acima de 0,5\%) (Fonte: Encyclopædia Britannica).

- Nos últimos doze meses assistiu a algum tipo de discriminação ou assédio baseado na origem étnica? (resposta relevante: sim) (fonte: Eurobarómetro).

3. Diversidade religiosa:

- Índice de diversidade religiosa (fonte: Pew Research Center).

- Religião ou confissão a que atualmente pertence (não católica) (fontes: ESS).

- Religião ou confissão a que pertenceu no passado (aplicável) (fontes: ESS).

- Pertença a grupos religiosos não católicos (\% total população) (fonte: WCD).

- Pertença a grupos não católicos (\% outras religiões e não religiões) (fonte: WCD).

4. Diversidade do local de nascimento:

- Cidadão do país (fonte: ESS).

- Nascido no país (fonte: ESS).

- Pai nascido no país (fonte: ESS).

- Mãe nascida no país (fonte: ESS).

- População estrangeira (fonte: OCDE).

- População nascida no estrangeiro (fonte: OCDE).

$\mathrm{Na}$ primeira dimensão tentámos seguir os principais indicadores linguísticos do Ethnologue, nomeadamente o número de línguas vivas e a sua cobertura nacional e a percentagem destas línguas que não é nativa. Não obstante o Ethnologue seja uma fonte normalmente citada por um grande número de linguistas, existe, segundo Paolillo (2006), um relativo consenso de que os seus dados têm algumas imprecisões, não raras vezes

Revista Cultura \& Religión Vol. XIII, 2019 № 2 (julio-diciembre)

Cómo citar este artículo: Botelho, J. (2019). "Diversidade cultural como secularização? Exame da correlação entre os índices de religiosidade e diversidade na Europa do século XXI”. Revista Cultura \& Religión.13(2). pp.75-102. 
problemáticas $^{8}$. Por isso, adicionámos um indicador do ESS que consideramos importante para entender o grau de diversidade linguística, mas também um índice de diversidade linguística ${ }^{9}$, compilado pela UNESCO e agregando os principais dados do Ethnologue. Esta complementaridade de dados e as diferentes formas de os trabalhar permite-nos refinar e dar maior solidez à nossa dimensão da diversidade linguística.

Por seu turno, a dimensão étnica provou ser, a mais desafiante. Por conta das suas imbricações com as dimensões linguísticas ou religiosa ou até mesmo com o local de nascimento, ela continua a ser analisada, principalmente na Encyclopadia Britannica, através de dimensões compostas como a etnolinguística ou a diversidade dos países de origem. Tendo em conta os nossos países selecionados ${ }^{10}$, isto sucede, respetivamente, nos casos italiano e austríaco. Além disso, nem todos os dados de todos os países estão atualizados nas mesmas datas ${ }^{11}$. Por este motivo, Patsiurko, Campbell e Hall (2012, p.196) referem que os seus dados apresentam "inconsistências". Isto deve-se, pelo menos em parte, ao facto de alguns países considerarem os dados sobre a etnicidade dos seus cidadãos como sensíveis e, por consequência, por colocarem barreiras legais à sua recolha (mesmo sob anonimato dos entrevistados). Para tentarmos contornar este problema complementámos os dados originais da Encyclopaedia Britannica, sobre a proporção do grupo de maioria étnica e sobre o número de etnias proporcionalmente relevantes, com os dados atualizados do World Directory of Minorities and Indigenous Peoples, repetindo inclusive (para lhe dar maior consistência, visto que é o item mais relevante nesta dimensão) o mesmo indicador sobre o grupo de maioria étnica. Selecionámos um item idêntico do Eurobarómetro, sobre a observação de discriminação étnica, que capta uma dimensão microssocial da fragmentação ou diversidade étnica e, enfim, um indicador sobre a autoidentificação étnica, disponibilizado pelo $\mathrm{ESS}^{12}$.

Relativamente à dimensão diversidade religiosa recorremos a bancos de dados já utilizados, principalmente, na construção do índice de religiosidade (o ESS e o WCD) ${ }^{13}$.

\footnotetext{
${ }^{8}$ Uma das principais críticas apontadas ao Ethnologue é que os seus valores, por norma, são mais altos do que noutras bases de dados. Isto deve-se, sobretudo, à sua definição de línguas que tende a incluir dialetos ou outras subcategorias duma determinada língua. Na construção dos nossos indicadores, de modo a evitarmos as implicações políticas e fluídas dos termos, considerámos o conceito lato de línguas vivas, determinado pelo Ethnologue.

${ }^{9}$ Este índice de diversidade linguística baseia-se no cálculo da proporção de cada língua, relativamente ao conjunto da população. Ou seja, considera o número de línguas distintas e a sua relativa frequência enquanto língua materna.

${ }^{10}$ Serão explicitados e justificados na próxima secção.

${ }^{11}$ Para a Áustria os dados recolhidos correspondem a 2015, os da Eslováquia a 2013, os da Polónia a 2011 e os de Itália, Espanha e Portugal a 2000.

${ }^{12}$ O ESS nas suas rondas 1 (2002) e 7 (2014) disponibiliza, como já referimos, dados sobre as dimensões nucleares da identidade étnica. Não os pudemos usar, porque a Itália não tem dados concernentes ao ano de 2014 e a Eslováquia não tem relativamente a 2002 e 2014.

${ }^{13}$ Sublinhamos que, embora os bancos de dados sejam os mesmos, nenhum dos indicadores da dimensão diversidade religiosa é idêntico a qualquer item no nosso índice de religiosidade. Garantimos, assim, que
}

\section{Revista Cultura \& Religión Vol. XIII, 2019 № 2 (julio-diciembre)}

Cómo citar este artículo: Botelho, J. (2019). "Diversidade cultural como secularização? Exame da correlação entre os índices de religiosidade e diversidade na Europa do século XXI”. Revista Cultura \& Religión.13(2). pp.75-102. 
Considerando que os países selecionados têm uma maioria nominal católica, nesta dimensão analisámos a diversidade religiosa não católica, ou seja a pertença a comunidades religiosas diferentes da católica. Também considerámos um indicador que examina, complementarmente, a fluidez e pluralidade da pertença religiosa, conseguindo assim captar a diversidade religiosa a partir doutro ângulo. Por fim, incluímos o índice de diversidade religiosa do Pew Research Center que, pela sua atualidade e amplitude, se tornou numa referência para os cientistas sociais, analisando e calculando a diversidade existente entre os oito principais grupos religiosos ao nível mundial. Este subíndice do Pew reforça, pelo seu refinamento metodológico, a nossa dimensão diversidade religiosa.

Finalmente, na dimensão sobre a diversidade do local de nascimento recolhemos dados no ESS e na OCDE, essencialmente através de indicadores que demonstrem os números da população não nativa, bem como dos seus ascendentes, de modo a captar em profundidade a heterogeneidade do local de nascimento. Importa ainda referir que, na composição desta dimensão, não recorremos (como sucede nas outras três dimensões da diversidade) a qualquer indicador/índice composto. Pelo seu desenvolvimento teórico relativamente tardio, ainda não foi construído qualquer índice por país. Por isso, ela é original e totalmente construída por nós.

Em suma, construímos um índice com quatro dimensões e 21 indicadores - todas as dimensões têm cinco itens, salvo a diversidade do local de nascimento que é composta por seis. Pelo número substancial de indicadores reunidos e pela sua criteriosa seleção e adequação ao tema que nos cumpre analisar, consideramos que os valores reunidos em torno deste índice serão representativos do nível de diversidade cultural de cada país.

\section{Proposta de composição e medição do índice de diversidade cultural}

Determinadas as dimensões e os 21 itens que medirão o nível de diversidade cultural nos nossos países selecionados, passamos à construção de um índice de diversidade (variável independente) que nos possibilitará correlacionar sua intensidade face à nossa variável dependente religiosidade.

Vimos estudando há uns anos o fenómeno religioso num grupo de países europeus. Temos investigado os fenómenos da secularização na Áustria, Eslováquia, Espanha, Itália, Polónia e Portugal ${ }^{14}$.

estamos a medir dimensões autónomas e que não há risco de estarmos a correlacionar (ainda que parcialmente) variáveis iguais.

${ }^{14}$ Tal como exige o rigor científico, a seleção deste grupo de países respeita critérios amplos e objetivos. $\mathrm{O}$ primeiro prende-se com o facto de todos os países terem separação Estado-religiões. Ou seja, um secularismo positivo ou passivo, no qual o Estado promove e permite a atividade e visibilidade das religiões no espaço

\section{Revista Cultura \& Religión Vol. XIII, 2019 N² 2 (julio-diciembre)}

Cómo citar este artículo: Botelho, J. (2019). "Diversidade cultural como secularização? Exame da correlação entre os índices de religiosidade e diversidade na Europa do século XXI”. Revista Cultura \& Religión.13(2). pp.75-102. 
No entanto, houve sempre dificuldades com o conceito de religião e, sobretudo, com as formas de medir a sua centralidade na vida dos indivíduos. Por conta disso propusemos, no passado recente, a criação teórica e empírica de um índice de religiosidade ${ }^{15}$ que servisse de variável dependente e que fosse correlacionável com variáveis independentes como a diversidade cultural.

Por esse motivo, na construção deste índice seguiremos a estratégia metodológica aplicada no índice de religiosidade. Isso permitirá comparar com os mesmos instrumentos os dois índices e desenvolver um marco teórico e empírico sobre a construção de um índice de diversidade cultural, algo sem precedentes no debate da secularização.

Assim sendo, consideramos necessária a criação de origem de um índice de diversidade cultural que nos permita validar ou eventualmente refutar, com base empírica, os argumentos dos teóricos da secularização. Para cumprir esse desiderato, cada variável de cada dimensão do nosso índice foi redimensionada para um intervalo de 1 a 10 (correspondentes ao valor mínimo e máximo de diversidade, respetivamente) e codificada consoante a escala criada para cada item. A opção por uma escala de 10 valores prende-se, principalmente, com a nossa preocupação com a maximização das diferenças entre os casos de estudo. De facto, eles foram selecionados com base no desenho de investigação dos sistemas mais similares, onde se comparam casos com características semelhantes. Se, de um lado, isso confere coerência à escolha dos nossos casos, favorecendo a constância das nossas variáveis; de outro lado, pode levar a variações de religiosidade e societalização impercetíveis entre eles. Para se evitar uma excessiva homogeneização desses cenários e para

público. O segundo concerne à sua tipologia de relacionamento Estado-religiões. Os casos de estudo estão perto do conceito de principled distance, na medida em que é permitido, legalmente, ao Estado um tratamento diferenciado das várias igrejas e comunidades religiosas. Esta tipologia é baseada na separação com lei especial, hierarquização de igrejas e liberdade religiosa. Em terceiro lugar, a nossa escolha foi baseada na sua condição sociorreligiosa. Selecionámos apenas países de maioria católica apostólica romana, mas onde se têm verificado fenómenos de mutação religiosa. Em particular, com o crescimento de minorias religiosas e não religiosas e a fusão dos dois - o fenómeno dos crentes sem religião. Por fim, os países selecionados são todos europeus, fazendo parte da região que mais mudanças tem vivido ao nível dos fluxos migratórios. O continente europeu é e, segundo os autores citados previamente, espera-se que continue a ser, um local de crescente diversidade cultural, por conta dos fenómenos de (i)migração global. É, portanto, uma região privilegiada para se analisar a força do impacto destes fenómenos na nossa variável dependente religiosidade. Para mais desenvolvimentos sobre estes critérios de seleção cf. Moniz (2016).

$15 \mathrm{O}$ nosso índice de religiosidade é uma medida multidimensional, dividida em cinco dimensões de religiosidade - intelectual, ideológica, ritual, devocional e experimental - e composta por 22 indicadores. Na construção deste índice usaram-se as bases de dados mais recentes do WCD - World Christian Database, do EVS - European Values Survey e do ESS - European Social Survey, aplicando-se ao nosso grupo de países selecionados. Os seus resultados são apresentados na figura 5, onde comparamos os níveis de religiosidade e societalização. Para mais desenvolvimentos sobre a metodologia aplicada na construção do índice cf. Moniz (2018).

\section{Revista Cultura \& Religión Vol. XIII, 2019 Nº 2 (julio-diciembre)}

Cómo citar este artículo: Botelho, J. (2019). "Diversidade cultural como secularização? Exame da correlação entre os índices de religiosidade e diversidade na Europa do século XXI”. Revista Cultura \& Religión.13(2). pp.75-102. 
se encontrar alguma variação, será útil o recurso a uma escala de 10 pontos, tal como Grim e Finke (2006) sugerem.

Cada um dos 21 itens do nosso modelo foi calculado através de um processo bastante simples, mas fiável. Primeiro multiplicamos por 100 o valor mínimo de cada item e depois dividimo-lo pelo valor máximo. Vejamos a tabela 1, relativamente ao indicador pai nascido no país.

\section{Tabela 1}

Exemplo de medição do item: Pai nascido no país

\begin{tabular}{lc}
\hline \multirow{2}{*}{ País } & \multicolumn{2}{c}{ Pai nascido no país } \\
\cline { 2 - 2 } & Valor médio bruto \\
\hline Áustria & 13,2 \\
\hline Itália & 3,1 \\
\hline Eslováquia & 4,6 \\
\hline Espanha & 8,6 \\
\hline Polónia & 3,2 \\
\hline Portugal & 5,3 \\
\hline
\end{tabular}

Fonte: ESS (2002-2014). Valores percentuais arredondados às décimas.

Na tabela 1, o $v b$ (valor médio bruto mais baixo) dos países selecionados é 3,1 e o va (valor médio bruto mais alto) é 13,2. Seguindo o nosso cálculo, 3,1 x 100 é igual a 310 que dividido por 13,2 dá o resultado aproximado de 23,48. A diferença entre 100 e esse valor $(23,48)$ equivale à percentagem aproximada de $77 \%$ que difere entre o $v b$ e o $v a$. A fórmula é, como frisámos, bastante simples (figura 1):

$$
X=\frac{v b \times 100}{v a}
$$

Figura 1: Formula baseada nos dados.

Para se comprovar que o valor de $X(76,52 \%)$ corresponde precisamente à diferença do valor médio bruto entre os $v a$ e $v b$, procedemos a outro cálculo elementar $[(\mathrm{X} \div 100) \mathrm{X}$ $v a]$. Assim sendo, a diferença entre ambos é 10,1, valor que corresponde exatamente à distância do valor médio bruto que aparta o $v a$ e o $v b$. Com o valor de $X$, pudemos começar a codificação das diferenças entre países por meio da nossa escala de 1 a 10 . A premissa básica da nossa codificação é fazer corresponder às diferenças entre os valores médio brutos a mesma diferença percentual da nossa escala de normalização. Deste modo, os valores

\section{Revista Cultura \& Religión Vol. XIII, 2019 N² 2 (julio-diciembre)}

Cómo citar este artículo: Botelho, J. (2019). "Diversidade cultural como secularização? Exame da correlação entre os índices de religiosidade e diversidade na Europa do século XXI”. Revista Cultura \& Religión.13(2). pp.75-102. 
médio brutos dos nossos itens foram reduzidos, mas a proporção das suas diferenças foi mantida.

Ressalvamos que nem sempre os indicadores disponíveis para a composição do nosso índice de diversidade cultural são analisados tão longitudinalmente quanto desejaríamos. Isso sucede, porque nem todos os itens, considerados relevantes para cada dimensão da diversidade, têm dados estatísticos para todos os anos de análise. No caso da tabela 1, cobrimos praticamente a totalidade dos anos selecionados, mas, por vezes, só temos dados disponíveis para intervalos temporais menores. Contudo, na sua maioria, os dados recolhidos e analisados abrangem o intervalo temporal completo de 16 anos do nosso estudo. Quer tenhamos, para cada item, um período temporal maior ou menor, os valores que, posteriormente, foram codificados são fruto da média aritmética simples de cada indicador. Por exemplo, no caso da tabela 1, o valor final de 8,6\% para Espanha foi encontrado através da média dos 7 valores anuais ${ }^{16}$, sendo que foi esse valor que foi acrescentado à tabela de codificação e que foi depois trabalhado através da nossa escala de normalização, visível no rodapé da tabela 2.

\section{Tabela 2}

Exemplo de pontuação do item: Pai nascido no país

\begin{tabular}{lcc}
\hline \multirow{2}{*}{ País } & \multicolumn{2}{c}{ Pai nascido no país } \\
\cline { 2 - 3 } & Valor médio bruto & Pontuação \\
\hline Áustria & 13,2 & 10 \\
\hline Itália & 3,1 & 2 \\
\hline Eslováquia & 4,6 & 3 \\
\hline Espanha & 8,6 & 7 \\
\hline Polónia & 3,2 & 2 \\
\hline Portugal & 5,3 & 4 \\
\hline Fonte: ESS $(2002-2014)$. Escala de normalização $(1-10): 1,9-2,8=1$ ponto; $2,9-$ \\
$3,8=2$ pontos; $3,9-4,8=3$ pontos; $4,9-5,8=4$ pontos; $5,9-6,8=5$ pontos; $6,9-$ \\
7,8=6 pontos; $7,9-8,8=7$ pontos; $8,9-9,8=8$ pontos; $9,9-10,8=9$ pontos; $10,9 »$ \\
$=10$ pontos.
\end{tabular}

A tabela 2 codifica com a pontuação $10 \mathrm{o} v a$ e com a pontuação $2 \mathrm{o} v b$. Entre eles existe uma diferença de 8 pontos que, se convertida para valores percentuais (neste caso, $80 \%$ ), se aproxima da diferença percentual real que os separa e que, neste indicador da diversidade, corresponde ao nosso valor aproximado de $X(77 \%)$. As demais diferenças percentuais entre os valores intermédios da figura, ou seja os valores que não são nem o $v b$ nem o va, foram respeitados, sempre que possível. Por exemplo, a diferença percentual entre

\footnotetext{
${ }^{16}$ Esses 7 valores anuais correspondem a cada uma das rondas, bianuais, do ESS, entre 2002 e 2014.
}

\section{Revista Cultura \& Religión Vol. XIII, 2019 № 2 (julio-diciembre)}

Cómo citar este artículo: Botelho, J. (2019). "Diversidade cultural como secularização? Exame da correlação entre os índices de religiosidade e diversidade na Europa do século XXI”. Revista Cultura \& Religión.13(2). pp.75-102. 
o caso austríaco e o espanhol é de aproximadamente $35 \%$. Na tabela 2 podemos reparar que o primeiro está codificado com a pontuação 10 e o segundo com a pontuação 7 . A diferença de 3 pontos (correspondentes a 30\%, se convertermos a nossa escala de normalização), corresponde aproximadamente à proporção da diferença entre ambos. No entanto, importa notar que este modelo tem as suas limitações. Nem todos os valores médios brutos correspondem, precisamente, à diferença percentual dos valores codificados. Apesar disso, os valores têm na maioria dos casos uma diferença máxima de um ponto ( $10 \%$ da diferença proporcional). As diferenças pontuais são, por isso, sempre mínimas, podendo estar um ponto para cima ou para baixo, comparativamente às diferenças percentuais reais.

Depois de descobrimos o valor de $X$ para cada indicador, utilizando a mesma fórmula matemática e a mesma metodologia, codificámos todos os itens da diversidade cultural, tal como demonstrado na tabela 3.

\section{Tabela 3}

\section{Codificação dos itens da diversidade em todas as dimensões}

\begin{tabular}{lccccccc}
\hline Diversidade & Áustria & Itália & Eslováquia & Espanha & Polónia & Portugal & Item \\
\hline & 10 & 6 & 4 & 5 & 1 & 1 & $\begin{array}{l}\text { Língua mais falada } \\
\text { em casa }\end{array}$ \\
& 8 & 10 & 7 & 4 & 3 & 6 & $\begin{array}{l}\text { Número de línguas } \\
\text { vivas }\end{array}$ \\
Linguística & 10 & 4 & 6 & 7 & 4 & 9 & $\begin{array}{l}\text { Número de línguas } \\
\text { vivas imigrantes }\end{array}$ \\
& 10 & 8 & 9 & 10 & 8 & 7 & $\begin{array}{l}\text { Cobertura territorial } \\
\text { da língua nativa }\end{array}$ \\
& 9 & 10 & 6 & 8 & 1 & 1 & $\begin{array}{l}\text { Índice de } \\
\text { diversidade } \\
\text { linguística }\end{array}$ \\
\hline Étnica & 8 & 2 & 10 & 5 & 3 & 4 & $\begin{array}{l}\text { Grupo étnico } \\
\text { minoritário no país } \\
\text { Grupo de maioria }\end{array}$ \\
& 6 & 5 & 6 & 10 & 5 & 5 & $\begin{array}{l}\text { étnica (nativa) } \\
\text { Grupo de maioria }\end{array}$ \\
& 7 & 7 & 8 & 10 & 7 & 7 & $\begin{array}{l}\text { étnica (nativa) } \\
\text { Número de etnias } \\
\text { relevantes }\end{array}$
\end{tabular}

Revista Cultura \& Religión Vol. XIII, 2019 № 2 (julio-diciembre)

Cómo citar este artículo: Botelho, J. (2019). "Diversidade cultural como secularização? Exame da correlação entre os índices de religiosidade e diversidade na Europa do século XXI”. Revista Cultura \& Religión.13(2). pp.75-102. 


\begin{tabular}{|c|c|c|c|c|c|c|c|}
\hline & 10 & 6 & 7 & 10 & 3 & 5 & $\begin{array}{l}\text { Discriminação ou } \\
\text { assédio baseado na } \\
\text { origem étnica }\end{array}$ \\
\hline \multirow{5}{*}{ Religiosa } & 9 & 8 & 7 & 10 & 3 & 3 & $\begin{array}{l}\text { Índice de diversidade } \\
\text { religiosa }\end{array}$ \\
\hline & 7 & 2 & 10 & 4 & 2 & 3 & $\begin{array}{l}\text { Religião ou confissão } \\
\text { a que pertence }\end{array}$ \\
\hline & 10 & 4 & 4 & 9 & 4 & 4 & $\begin{array}{l}\text { Religião ou confissão } \\
\text { a que pertenceu }\end{array}$ \\
\hline & 10 & 4 & 7 & 3 & 6 & 9 & $\begin{array}{l}\text { Pertença a grupo } \\
\text { religiosos não } \\
\text { católicos }\end{array}$ \\
\hline & 10 & 6 & 7 & 4 & 3 & 4 & $\begin{array}{l}\text { Pertença a religiões } \\
\text { não católicas e a não } \\
\text { religiões }\end{array}$ \\
\hline \multirow{6}{*}{$\begin{array}{l}\text { Local } \\
\text { de } \\
\text { nascimento }\end{array}$} & 7 & 2 & 1 & 10 & 1 & 5 & Cidadão do país \\
\hline & 10 & 4 & 2 & 10 & 1 & 7 & Nascido no país \\
\hline & 10 & 2 & 3 & 7 & 2 & 4 & Pai nascido no país \\
\hline & 10 & 2 & 3 & 7 & 2 & 4 & Mãe nascida no país \\
\hline & 10 & 6 & 1 & 10 & 1 & 4 & $\begin{array}{l}\text { População } \\
\text { estrangeira }\end{array}$ \\
\hline & 10 & 5 & 2 & 9 & 1 & 6 & $\begin{array}{l}\text { População nascida no } \\
\text { estrangeiro }\end{array}$ \\
\hline Total & 189 & 110 & 118 & 162 & 65 & 106 & \\
\hline
\end{tabular}

Fonte: compilação do autor, considerando as fontes já citadas

Para o conjunto dos nossos indicadores, a maior pontuação possível, por país, é de 210. Uma maior proximidade deste valor significa um maior nível de diversidade. Na tabela 3 podemos observar que os valores são relativamente díspares. A Áustria surge, destacadamente, como o país mais diverso culturalmente, recolhendo 189 em 210 pontos possíveis. Por seu turno, a Polónia é, de longe, o país com menos diversidade, apresentando apenas 65 pontos. A Espanha é o segundo país com maior grau de diversidade, reunindo 162 pontos e estando longe de Eslováquia (118), Itália (110) e Portugal (106) que são os países que lhe seguem, respetivamente. Embora estes valores brutos nos deem já uma perspetiva das diferenças, ao nível da diversidade, entre os países, de modo a garantirmos que nenhuma

\section{Revista Cultura \& Religión Vol. XIII, 2019 № 2 (julio-diciembre)}

Cómo citar este artículo: Botelho, J. (2019). "Diversidade cultural como secularização? Exame da correlação entre os índices de religiosidade e diversidade na Europa do século XXI”. Revista Cultura \& Religión.13(2). pp.75-102. 
dimensão tem mais peso do que outra na quantificação final, ponderámos a média aritmética simples das quatro dimensões ${ }^{17}$. Observe-se a tabela 4.

\section{Tabela 4}

Média aritmética de cada dimensão de diversidade

\begin{tabular}{lcccccc}
\hline Diversidade & Áustria & Itália & Eslováquia & Espanha & Polónia & Portugal \\
\hline Linguística & 9,4 & 7,6 & 6,4 & 6,8 & 3,4 & 4,8 \\
Étnica & 7,8 & 5,4 & 7,8 & 9,0 & 4,4 & 5,8 \\
Religiosa & 9,2 & 4,8 & 7,0 & 6,0 & 3,6 & 4,6 \\
Local de & 9,5 & 3,5 & 2,0 & 8,8 & 1,3 & 5,0 \\
nascimento & & & & & & \\
\hline Médias & 9,0 & 5,3 & 5,8 & 7,7 & 3,2 & 5,1 \\
\hline
\end{tabular}

Fonte: compilação do autor, considerando as fontes já citadas

Como podemos notar, não existe qualquer alteração relativamente ao posicionamento dos países. Isto deve-se ao facto de as dimensões da diversidade terem, cada uma, no nosso modelo, praticamente o mesmo número de indicadores - apenas a dimensão local de nascimento tem mais um item (seis) do que as outras (cinco cada uma). Todavia, este passo metodológico permitiu-nos refinar os valores finais, maximizando, ainda que não em todos os casos, as diferenças entre os países ${ }^{18}$. Isso é importante, porque permite encontrar valores de diversidade mais rigorosos, acentuar as diferenças nos seus níveis e definir intervalos/níveis de classificação entre os países. Deste modo, estabelecemos cinco níveis de diversidade cultural: entre 1,0 e 2,9 - muito baixa; entre 3,0 e 4,9 - baixa (caso da Polónia); entre 5,0 e 6,9 - média (em ordem crescente, casos de Portugal, Itália e Eslováquia); entre 7,0 e 8,9 - alta (caso da Espanha); e entre 9,0 e 10 - muito alta (caso da Áustria).

Através do índice de diversidade verificamos uma grande segmentação entre países. Áustria e Polónia apresentam a melhor e a pior pontuação, respetivamente. O primeiro encontra-se num extremo (muito alto) da nossa grelha classificativa, enquanto o segundo está muito próximo do seu outro extremo (muito baixo). A Espanha surge igualmente isolada na categoria de diversidade alta, estando bastante distante dos outros três países que estão mais próximos, nomeadamente Portugal e Itália, dum nível médio-baixo. Assim, podemos sublinhar a existência de três grupos de países: os altamente diversificados (Áustria e

\footnotetext{
${ }^{17}$ A opção por uma média aritmética simples deve-se ao facto de nenhuma das dimensões ou dos indicadores deste índice, bem como dos demais, ser considerada mais influente ou relevante do que outra, como tal todas têm o mesmo peso na composição do índice.

${ }^{18}$ Por exemplo, se na tabela 3 a diferença entre Itália e Eslováquia era de 7\%, na tabela 4 essa disparidade aumentou para os $8,6 \%$. Contudo, a maioria das diferenças entre os países manteve-se inalterada, tendo até diminuído $(1,1 \%)$ entre Áustria e Polónia.
}

\section{Revista Cultura \& Religión Vol. XIII, 2019 N² 2 (julio-diciembre)}

Cómo citar este artículo: Botelho, J. (2019). "Diversidade cultural como secularização? Exame da correlação entre os índices de religiosidade e diversidade na Europa do século XXI”. Revista Cultura \& Religión.13(2). pp.75-102. 
Espanha), os medianamente diversificados (Eslováquia, Itália e Portugal) e o baixamente diversificado (Polónia).

A análise individual das dimensões da diversidade permite-nos entender melhor estes valores. Com efeito, o caso austríaco tem, à exceção da dimensão étnica, todas as suas dimensões de diversidade em categorias muito altas, destacando-se a dimensão local de nascimento, onde tem uma pontuação muito alta em cinco dos seis indicadores que a compõem. Por seu turno, a Espanha apresenta a pontuação mais elevada na dimensão étnica, sendo o único país a situar-se num patamar de diversidade muito alto. Contudo, o caso espanhol apresenta apenas valores médios nas dimensões de diversidade linguística ou religiosa, contribuindo para isso, sobretudo, a sua fraca pontuação nos indicadores número de línguas vivas ou pertença a grupo religiosos não católicos. A Eslováquia tem valores próximos aos de Espanha, sendo ainda significativamente mais diversa na dimensão religiosa. Todavia, na dimensão sobre a diversidade do local de nascimento, o caso eslovaco é o segundo mais pequeno, estando à semelhança da Polónia num patamar de diversidade muito baixo, o que o afasta definitivamente do caso espanhol. Isto deve-se, em especial, à sua pontuação muito baixa nos indicadores cidadão do país ou população estrangeira. A Polónia, no outro extremo da tabela classificativa, tem em todas as dimensões da diversidade a pontuação mais fraca, destacando-se pelo seu nível muito baixo de diversidade do local de nascimento, onde só tem pontuações entre 1 e 2 . A Itália, embora seja o segundo país com maior diversidade linguística, tem as segundas piores pontuações nas dimensões de diversidade étnica e do local de nascimento, sendo aliás o país com pior pontuação no indicador pertença a grupo étnico minoritário no país. Portugal é o segundo país com pior pontuação nas dimensões de diversidade linguística e religiosa.

Contudo, apresenta a maior consistência relativa, em termos pontuais, em todas as dimensões. Todas as suas dimensões estão dentro de intervalos classificativos baixos-altos ou médio-baixos e a maior diferença pontual existente entre dimensões é de apenas 1,2.

Em suma, destacamos que Áustria e Espanha são os países com maiores índices de diversidade, agregando, entre si, 25 indicadores que estão no intervalo de diversidade muito alta. Eles reúnem quase $80 \%$ do conjunto destes indicadores, estando espalhados, de forma mais ou menos equilibrada, por todas as dimensões da diversidade. Inversamente, a Polónia, o país com menos diversidade, reúne 9 indicadores do intervalo de diversidade muito baixa, $45 \%$ do total. Estes itens concentram-se, principalmente, na dimensão sobre a diversidade do local de nascimento. Os outros países, com a exceção da Itália ou da Eslováquia, nas dimensões sobre a diversidade linguística e religiosa, respetivamente, contribuem mais com itens de diversidade baixa ou muito baixa do que com itens de diversidade alta ou muito alta.

Revista Cultura \& Religión Vol. XIII, 2019 N² 2 (julio-diciembre)

Cómo citar este artículo: Botelho, J. (2019). "Diversidade cultural como secularização? Exame da correlação entre os índices de religiosidade e diversidade na Europa do século XXI”. Revista Cultura \& Religión.13(2). pp.75-102. 


\section{Correlação entre diversidade cultural e religiosidade}

É chegado o momento de compararmos o índice de diversidade com a nossa variável dependente - o índice de religiosidade. Procuramos entender qual dos argumentos habitualmente citados sobre os efeitos da diversidade na religiosidade (mais diversidade significa menos religião, mais diversidade significa mais religião, diversidade não tem efeitos na religião ou diversidade tem efeitos tendencialmente negativos na religião, mas isso não a enfraquece) é corroborado empiricamente pelos nossos dados. Para começarmos a testar empiricamente estas proposições, vejamos a figura 2.

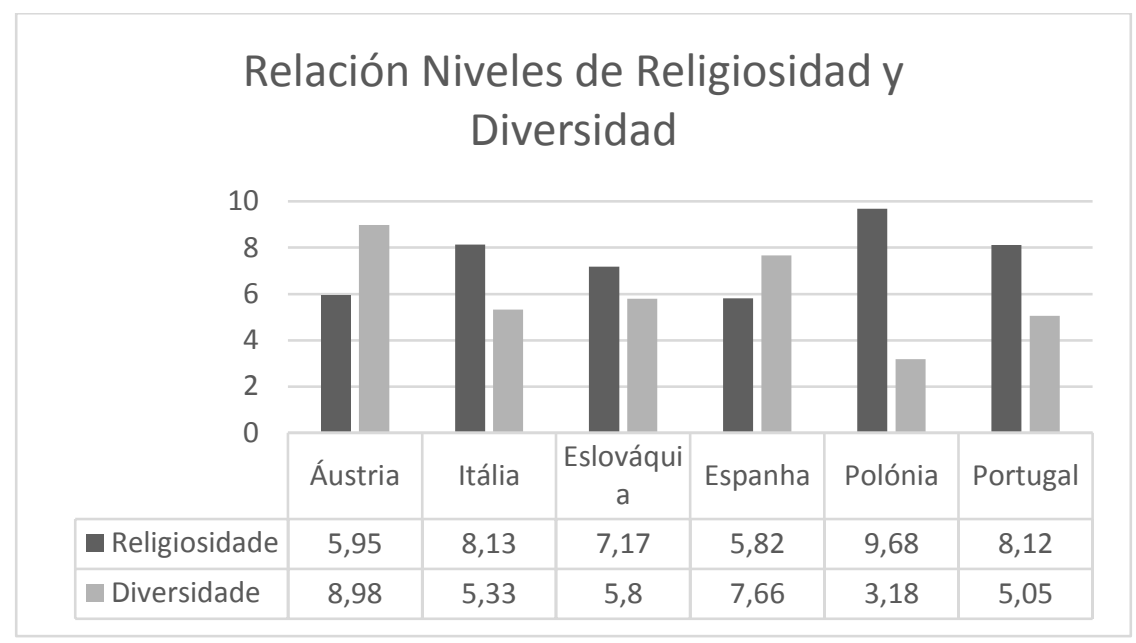

Figura 2: Colunas com a relação entre os níveis de religiosidade e de diversidade. Fonte: compilação do autor, considerando as fontes já citadas.

A observação da figura 2 permite-nos verificar rapidamente que os países com menores índices de diversidade (descendentemente, Itália, Portugal e Polónia) são os mais religiosos. Por consequência, os países com maiores índices de diversidade (ascendentemente, Eslováquia, Espanha e Áustria) são os menos religiosos. O recurso aos nossos intervalos classificativos, permite-nos esclarecer que, por exemplo, Espanha e Áustria, os únicos países com um valor médio de religiosidade (o mais baixo do conjunto), são os que têm índices de diversidade altos ou muito altos, respetivamente. Por seu turno, a Polónia, o único país com uma taxa de religiosidade muito alta, é também o único com um índice de diversidade baixo. As proposições que dizem que mais diversidade significa tendencialmente menos religião têm, por isso, eco na nossa investigação. De facto, existe uma relação negativa quase perfeita entre as duas variáveis. À exceção da Áustria e Espanha, a ordem classificativa é total e negativamente respeitada: o país (Polónia) com maior classificação na religiosidade é o sexto e último classificado em termos de diversidade; o segundo país com maior pontuação em termos de religiosidade é o quinto e penúltimo em matéria de diversidade, e assim por diante. De modo a entendermos melhor essa relação negativa entre as variáveis, observe-se a figura 3.

\section{Revista Cultura \& Religión Vol. XIII, 2019 N 2 (julio-diciembre)}

Cómo citar este artículo: Botelho, J. (2019). "Diversidade cultural como secularização? Exame da correlação entre os índices de religiosidade e diversidade na Europa do século XXI”. Revista Cultura \& Religión.13(2). pp.75-102. 


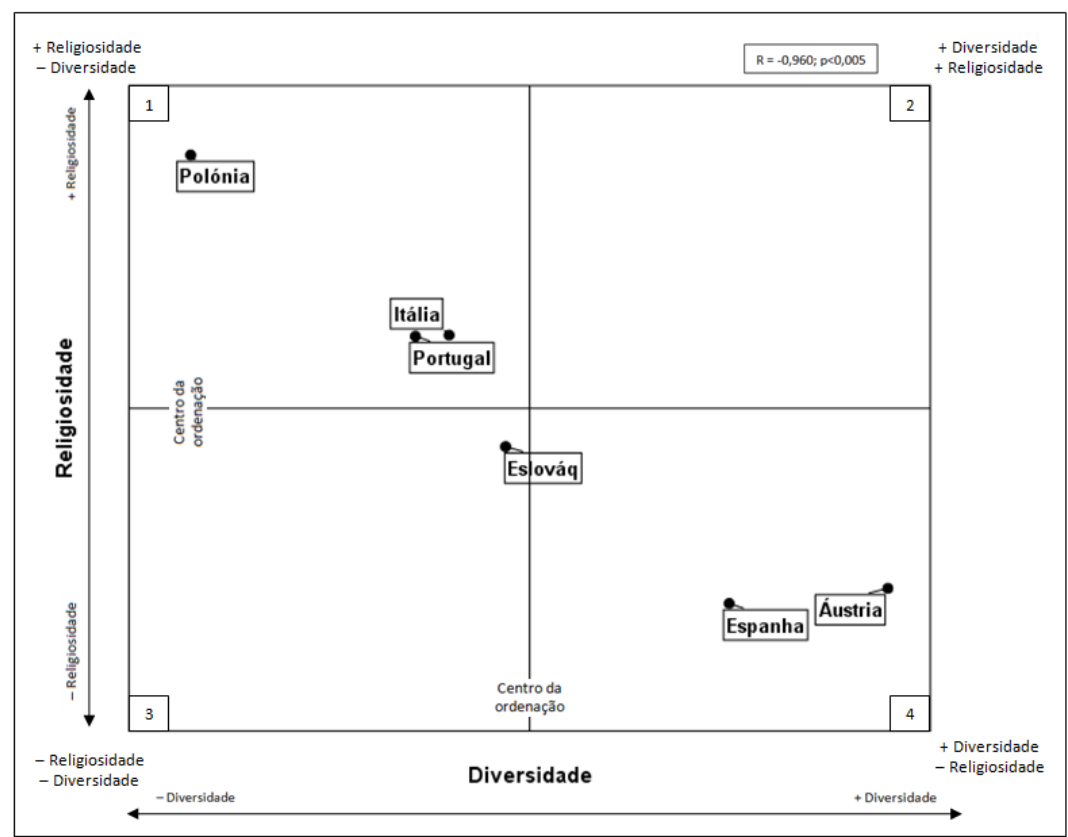

Figura 3: Religiosidade $v s$. Diversidade (posição relativa dos países na respetiva ordenação). Fonte: cálculos do autor, considerando as fontes já citadas

$\mathrm{Na}$ figura 3 examinamos a correlação entre o índice de religiosidade e o de diversidade. A análise da posição relativa dos casos de estudo revela mais distintamente o que a figura 5 já denunciava: existe uma correlação negativa muito forte e estatisticamente significativa entre as duas variáveis $(r(6)=-0,960 ; p<0,01)^{19}$. Isto é, a teoria da diversidade ajuda a explicar, quase na perfeição, a variação (negativa) da religiosidade (96\%), considerando os países escolhidos e a metodologia aplicada.

De facto, a figura 3 prova a correlação negativa muito forte entre diversidade e religiosidade. Se olharmos para os quadrantes do gráfico, verificamos que os três países mais religiosos estão situados no quadrante 1 (mais religiosidade e menos diversidade), enquanto os menos religiosos se encontram no quadrante 4 (mais diversidade e menos religiosidade). A Eslováquia é o único país que se encontra isolado num quadrante (o número 3: menos religiosidade e menos diversidade), mas, pela sua proximidade do quadrante 4 e pela sua linearidade (negativa) com os outros países, não deve ser considerado um caso desviante do modelo. A nossa categorização por quadrantes comprova muito fortemente as proposições dos teóricos da secularização relativamente à diversidade: quanto maior o nível de diversidade dum país menor o seu nível de religiosidade. Ou seja, mais diversidade significa menos religiosidade. A diversidade parece estar negativamente associada ao desenvolvimento da religião, conduzindo, de acordo com os nossos dados, ao

${ }^{19} \mathrm{O}$ valor do nível de significância é precisamente ,002.

\section{Revista Cultura \& Religión Vol. XIII, 2019 N² 2 (julio-diciembre)}

Cómo citar este artículo: Botelho, J. (2019). "Diversidade cultural como secularização? Exame da correlação entre os índices de religiosidade e diversidade na Europa do século XXI”. Revista Cultura \& Religión.13(2). pp.75-102. 
enfraquecimento da última. Inversamente, as teorias que defendem que a diversidade é benéfica para a religião não são, de todo, atestadas pela nossa investigação. Prova disso é o facto de o quadrante 2 (mais diversidade e mais religiosidade) ser o único vazio. De igual modo, as teorias que defendem a inexistência de relação entre estas variáveis são insustentáveis, considerando estes resultados. Existe aqui uma correlação (no caso, negativa) muito forte entre diversidade e religiosidade. Por fim, interessa-nos examinar, individualmente, a correlação entre a religiosidade e cada uma das dimensões da diversidade, de modo a entendermos a negatividade ou positividade da sua relação e a percebermos qual delas se correlaciona mais fortemente com a variável dependente. Analisemos então a tabela 5 .

\section{Tabela 5}

Correlações entre a religiosidade e as dimensões da diversidade

\begin{tabular}{lcccc}
\hline \multirow{2}{*}{ Religiosidade } & \multicolumn{4}{c}{ Diversidade } \\
\cline { 2 - 5 } & Linguística & Étnica & Religiosa & $\begin{array}{c}\text { Local de } \\
\text { nascimento }\end{array}$ \\
\hline Correlação de &,$- 780^{*}$ &,$- 950^{* * *}$ &,$- 819^{* *}$ &,$- 840^{* *}$ \\
Pearson & & & &, 036 \\
Sig. (bilateral) &, 067 &, 004 &, 046 & 6 \\
$\mathrm{~N}$ & 6 & 6 & 6 & 6 \\
\hline
\end{tabular}

Nota: *As correlações são significativas no nível 0,10 (bilateral); ** As correlações são significativas no nível 0,05 (bilateral); *** As correlações são significativas no nível 0,01 (bilateral)

O primeiro aspeto que realçamos é o facto de todas as dimensões da diversidade apresentarem, no mínimo, correlações negativas fortes com a religiosidade, sendo todas estatisticamente significativas. Independentemente do ângulo da diversidade empregue na correlação com a religião, o impacto da primeira é sempre fortemente negativo na última. $\mathrm{O}$ segundo ponto que enfatizamos é a correlação negativa muito forte entre a diversidade étnica e a religiosidade, sendo estatisticamente significativa $(r(6)=-.950 ; p<0,01)$. Tal como Alesina et al. (2003) declararam, a etnicidade é a principal dimensão de análise da diversidade. Realçamos ainda a sua proximidade com a correlação negativa muito forte do índice global de diversidade que viemos analisando (como vimos, $[r(6)=-0,960 ; p<0,01]$ ). Isso poder-nos-ia levar a cogitar que a dimensão étnica da diversidade, por si só, capta o essencial da relação entre diversidade e religiosidade. Pelo contrário, a dimensão linguística da diversidade é a que menor correlação negativa tem com a religiosidade; porém, é ainda estatisticamente significativa $(r(6)=-780 ; p<0,10)^{20}$. Isto deve-se essencialmente ao facto

\footnotetext{
${ }^{20}$ Dada a pequena dimensão da nossa amostra, apenas seis países, consideraremos significativas as correlações que tenham um intervalo de confiança de até $90 \%$ : $\mathrm{p}<0,10$. Ainda que procuremos sempre dar maior ênfase às correlações com intervalos de confiança menores, nomeadamente àquelas dentro do valor convencionado de
}

\section{Revista Cultura \& Religión Vol. XIII, 2019 № 2 (julio-diciembre)}

Cómo citar este artículo: Botelho, J. (2019). "Diversidade cultural como secularização? Exame da correlação entre os índices de religiosidade e diversidade na Europa do século XXI”. Revista Cultura \& Religión.13(2). pp.75-102. 
de a Itália, o segundo país mais religioso do conjunto, ser também o segundo mais diverso nesse campo. Efetivamente, se retirássemos o caso italiano desta dimensão, já obteríamos praticamente uma correlação negativa muito forte entre as variáveis ${ }^{21}$. A separação das dimensões étnica e linguística da diversidade, proposta por Alesina et al. (2003), mostrou-se então útil, porque indica que são esferas distintas da diversidade que, por consequência, têm impactos não coincidentes na variável dependente.

Falemos ainda das duas outras dimensões da diversidade. A religiosa, contrariamente ao que os teóricos dos estudos económicos apontam, tem uma forte correlação com a variável dependente, sendo estatisticamente significativa $(r(6)=-.819 ; p<0,05)$. $\mathrm{O}$ aditamento da dimensão local de nascimento, sugerida por Ottaviano e Peri (2006) ou Dohse e Gold (2013), também se mostrou profícua, visto que é a segunda dimensão da diversidade que mais se correlaciona com a religiosidade, sendo estatisticamente significativa $(r(6)=-.840 ; p<0,05)$. Contudo, por oposição ao que Alesina, Harnoss e Rapoport (2016) asseveraram, esta dimensão tem, à semelhança das outras da diversidade, uma correlação similarmente forte com a variável dependente.

Assim sendo, dadas as correlações negativas fortes e muito fortes do nosso modelo, podemos afirmar três aspetos essenciais relativamente ao estado da arte - ainda que não recorra a um conceito de diversidade multidimensional como nós propomos. Em primeiro lugar, no campo teórico, os nossos dados não corroboram as proposições dos teóricos da economia religiosa que dizem que quanto maior a diversidade de escolhas religiosas, mais a religião tende a florescer. Pelo contrário, os nossos dados demonstram, quer analisemos apenas a dimensão religiosa da diversidade ou todas as suas quatro dimensões, que esta relação é, sem exceções, totalmente oposta: a diversidade está sempre negativamente correlacionada com a religião.

Por outro lado, isso significa, em consonância com as teorias clássicas da secularização (por exemplo, Berger, 1990 [1967]) ou com algumas das suas teorizações mais recentes (por exemplo, Taylor, 2007; Berger, 2014), que a diversidade conduz a uma contaminação, diferenciação ou fragilização dos valores sociais, enfraquecendo, por conseguinte, as cosmovisões religiosas. Em segundo lugar, no campo empírico, o nosso estudo não apoia as teses que falam duma relação tendencialmente nula entre diversidade e religião (Voas, Olson e Crockett, 2002; Norris e Inglehart, 2004). Os nossos dados apontam, inversamente, na direção dos trabalhos de Doktór (2009) ou Pollack e Pickel (2009), especialmente para as suas conclusões sobre os impactos negativos da diversidade na religião. Em terceiro lugar, os nossos resultados aproximam-se das teses que defendem que a diversidade tem efeitos, tendencialmente negativos, na religiosidade e que essa realidade é

$95 \%, \mathrm{p}<0,05$, pela nossa pequena dimensão amostral, pelo foco exploratório deste trabalho, um limite de referência $\mathrm{p}<0,10$ pode sugerir um efeito significativo que deverá ser alvo de maior aprofundamento futuro.

${ }^{21}$ Essa correlação seria a seguinte: $r(6)=-896$; $p<0,05$.

\section{Revista Cultura \& Religión Vol. XIII, 2019 № 2 (julio-diciembre)}

Cómo citar este artículo: Botelho, J. (2019). "Diversidade cultural como secularização? Exame da correlação entre os índices de religiosidade e diversidade na Europa do século XXI”. Revista Cultura \& Religión.13(2). pp.75-102. 
incontornável para se compreender o lugar da religião nas sociedades contemporâneas (Norris e Inglehart, 2004; Berger, 2014). Contudo, o nosso estudo não permite corroborar a hipótese destes mesmos teóricos que assume implicitamente a religião como uma constante antropológica que nenhum processo da modernidade é capaz de abalar, mas apenas fazer mover e adaptar. Pelo contrário, os nossos dados sugerem um enfraquecimento geral da religiosidade à medida que as sociedades se diversificam culturalmente.

Embora não concluamos categoricamente, como Pickel (2017), que a diversidade tem consequências arrasadoras para a relevância do religioso, a nossa investigação permite-nos dizer, com segurança, que a diversidade tem consequências negativas para a religião. Julgamos que este contributo empírico é importante, porque pode ajudar os atuais teóricos da secularização a concluir mais assertivamente - o que é diferente de unívoca, determinística ou universalmente - aquilo que vêm dizendo de forma implícita nos seus trabalhos (Norris e Inglehart, 2004; Berger, 2014). Ou seja, a diversidade tem impactos na religião que vão além da mera mutação ou recomposição do religioso em condições modernas, sugerida por outros autores (Berger, Davie e Fokas, 2008; Berger, 2014; Vilaça et al., 2014).

\section{Comentário final}

O nosso estudo permitiu-nos concluir que, para o conjunto dos países analisados e através da metodologia aplicada, a teoria da secularização, que diz que as sociedades mais diferenciadas culturalmente são menos religiosas, tem validade empírica. Com efeito, os nossos dados mostram que a diversidade cultural explica cerca de $96 \%$ da variação (negativa) na religiosidade. Isto é, a diversidade cultural tem, em todas as suas dimensões, um impacto negativo na religiosidade. As proposições sobre o modo como a diversidade, por meio das suas várias dimensões, tende a romper a homogeneidade cultural e a fragmentar as estruturas de plausibilidade da religião, tornando-a apenas em mais uma opção social entre muitas outras, têm portanto ressonância empírica.

Além disso, dadas as correlações negativas fortes e muito fortes do nosso modelo, podemos afirmar três aspetos essenciais relativamente ao estado da arte - ainda que não recorra a um conceito de diversidade multidimensional como nós propomos. Em primeiro lugar, no campo teórico, os nossos dados não corroboram as proposições dos teóricos da economia religiosa que dizem que quanto maior a diversidade de escolhas religiosas, mais a religião tende a florescer.

Pelo contrário, os nossos dados demonstram, quer analisemos apenas a dimensão religiosa da diversidade ou todas as suas quatro dimensões, que esta relação é, sem exceções, totalmente oposta: a diversidade está sempre negativamente correlacionada com a religião. Por outro lado, isso significa, em consonância com as teorias clássicas da secularização ou com algumas das suas teorizações mais recentes, que a diversidade conduz a uma

\section{Revista Cultura \& Religión Vol. XIII, 2019 Nº 2 (julio-diciembre)}

Cómo citar este artículo: Botelho, J. (2019). "Diversidade cultural como secularização? Exame da correlação entre os índices de religiosidade e diversidade na Europa do século XXI”. Revista Cultura \& Religión.13(2). pp.75-102. 
contaminação, diferenciação ou fragilização dos valores sociais, enfraquecendo, por conseguinte, as cosmovisões religiosas. Em segundo lugar, no campo empírico, o nosso estudo não apoia as teses que falam duma relação tendencialmente nula entre diversidade e religião. Os nossos dados apontam, inversamente, na direção dos trabalhos de Doktór (2009) ou Pollack e Pickel (2009), especialmente para as suas conclusões sobre os impactos negativos da diversidade na religião. Em terceiro lugar, os nossos resultados aproximam-se das teses que defendem que a diversidade tem efeitos, tendencialmente negativos, na religiosidade e que essa realidade é incontornável para se compreender o lugar da religião nas sociedades contemporâneas. Contudo, o nosso estudo não permite corroborar a hipótese destes mesmos teóricos que assume, implicitamente, a religião como uma constante antropológica que nenhum processo da modernidade é capaz de abalar, mas apenas fazer mover e adaptar. Pelo contrário, os nossos dados sugerem um enfraquecimento geral da religiosidade à medida que as sociedades se diversificam culturalmente. Isto não significa, porém, que à secularização da sociedade corresponda necessariamente o declínio ou, no limite, o fïm da religião. Tal como nos ensina Weber, os indivíduos, em condições modernas, não conseguem viver com a religião, mas também não conseguem viver sem ela. Esta é a complexidade dos nossos tempos - a religião pode passar simultaneamente por declínio, mutação e ressurgimento. A inevitabilidade das teorias da secularização está, portanto, aberta a debate e revisão.

Atualmente, estas são ainda águas desconhecidas, cujos resultados da navegação ninguém pode prever. $\mathrm{O}$ que sabemos é que os processos da modernidade, descritos pelos teóricos da diversidade, não parecem ter impactos positivos na religião, antes pelo contrário. A modernidade e, em particular, a diversidade correlacionam-se muito negativamente com a religião, diminuindo, direta ou indiretamente, o seu significado social. A fragmentação das certezas absolutas que a diversidade provoca, nomeada mas não exclusivamente, na religião, pode aumentar a probabilidade dos indivíduos escolherem opções seculares no seu quotidiano, aprofundando, consequentemente, os níveis de iliteracia religiosa e afetando, derradeiramente, a relevância individual e social da religião. Não há, porém, razões para acreditarmos que iremos assistir, mesmo com a disseminação e o aprofundamento dos fenómenos de diversidade, a um processo linear de declínio - uma perda arrasadora de relevância da religião, nas palavras proféticas de Pickel (2017). Todavia, neste contexto, a ideia de um reavivar religioso parece ainda mais improvável. Se, por um lado, acreditamos, pelos resultados reunidos, que a secularização está a acontecer e que afeta a e é afetada pela religião (ainda que em menor dimensão); por outro lado, julgamos que o desfecho previsto pelas suas grandes narrativas, quanto ao fatalismo do declínio ou perecimento do religioso, está errado.

Este trabalho é apenas um primeiro passo para compreendermos os impactos destas novas dinâmicas sociais na religião. Será ainda necessário aumentar as bases de dados disponíveis e, por consequência, refinar os modelos de construção de índices. Será preciso

Revista Cultura \& Religión Vol. XIII, 2019 № 2 (julio-diciembre)

Cómo citar este artículo: Botelho, J. (2019). "Diversidade cultural como secularização? Exame da correlação entre os índices de religiosidade e diversidade na Europa do século XXI”. Revista Cultura \& Religión.13(2). pp.75-102. 
estudar outras variáveis independentes relevantes, como as teorias clássicas (racionalização, societalização e diferenciação funcional) da secularização ou as suas atualizações teóricas (segurança existencial).

Será fundamental explorar novas grelhas analíticas, como a economia global, os mass media digitais ou o terrorismo. Será inevitável examinar diferentes contextos regionais, englobando mais países (cuja comparação se justifique e seja cientificamente relevante) nas análises empíricas. No fundo, como nos disse profeticamente Berger (2014), será necessário estudar os vários altares da modernidade, religiosos ou não religiosos, e entender a posição (mutável e que tanto pode significar revitalização, declínio ou transformação) da religião nas sociedades hodiernas. Deixamos, portanto, esses reptos aos cientistas sociais que estejam tão empenhados quanto nós em entender os efeitos (positivos ou negativos) dos processos da modernidade na religiosidade.

\section{Referências}

Alemu, A. (2016). "The Impacts of Ethnic, Linguistic and Religious Fractionalization on State Fragility in Africa". Journal of Marketing \& Management, 7(2). pp. 47-66.

Alesina, A., et al. (2003). "Fractionalization". em Journal of Economic Growth. № 8. pp. 155-194.

Alesina, A.; Harnoss, J. \& Rapoport, H. (2016). "Birthplace diversity and economic prosperity". Journal of Economic Growth, 2(2). pp. 101-138.

Beckford, J. (2003). Social Theory and Religion. Cambridge: Cambridge University Press.

Berger, P. L. (1990/1967). The sacred canopy: Elements of a sociological theory of religion. Nova Iorque, Anchor Books.

Berger, P. L. (2014). The Many Altars of Modernity: Toward a Paradigm for Religion in a Pluralist Age. Boston/Berlim: De Gruyter.

Berger, P. L, Davie, G. \& Fokas, E. (2008). Religious America, Secular Europe?: A Theme and Variation. Aldershot: Ashgate Publishing.

Casanova, J. (2007). "Reconsiderar la Secularización: Una perspectiva comparada mundial"Revista Académica de Relaciones Internacionales. 7(1). pp. 1-20.

Crystal, D. (2002). Language Death. Cambridge: Cambridge University Press.

Dohse, D. \& Gold, R. (2013). "Measuring Cultural Diversity at a Regional Level”, visitado 14 de junho de 2019 (http://www.foreurope.eu/fileadmin/documents/pdf/Workingpapers/WWWforEurop e_WPS_no010_MS99.pdf).

Doktór, Tadeusz. (2009). "Religious pluralism and dimensions of religiosity: evidence from the project Religious and Moral Pluralism (RAMP)". Church and Religion in Contemporary Europe: Results from Empirical and Comparative Research (pp. 2534). Gert Pickel \& Olaf Müller (editores). Wiesbaden: VS Verlag.

Revista Cultura \& Religión Vol. XIII, 2019 N² 2 (julio-diciembre)

Cómo citar este artículo: Botelho, J. (2019). "Diversidade cultural como secularização? Exame da correlação entre os índices de religiosidade e diversidade na Europa do século XXI”. Revista Cultura \& Religión.13(2). pp.75-102. 
Erikson, R., Jonnson, J. (1999). "How to ascertain the socio-structural position of the individual in society. Suggestions for the core ESS questions", visitado em 14 de

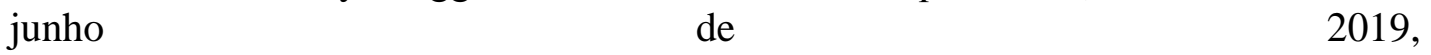
(https://www.europeansocialsurvey.org/docs/methodology/core_ess_questionnaire/ ESS_core_questionnaire_measuring_social_structure.pdf).

Fearon, J. D. (2003). "Ethnic and Cultural Diversity by Country" Journal of Economic Growth. 8(2). pp. 195-222.

Gardenswartz, L. \& Rowe, A. (2003). "Four layers of diversity", visitado em 14 de junho de 2019 (https://www.gardenswartzrowe.com/why-g-r).

Gören, E. (2014). "How Ethnic Diversity Affects Economic Growth" World Development. 59(1). pp. 275-297.

Grim, B. \& Finke, R. (2006). "International Religion Indexes: Government Regulation, Government Favoritism, and Social Regulation of Religion”. Interdisciplinary Journal of Research on Religion. 2(1). pp. 1-40.

Halikiopoulou, D. (2011). Patterns of Secularization: Church, State and Nation in Greece and the Republic of Ireland. Farnham: Ashgate.Johnson, T. \& Grim, B. (2013). The World's Religions in Figures: An Introduction to International Religious Demography. West Sussex: Wiley-Blackwell.

Machado, M. D. C. (2007). “Globalización y secularización”. Revista Cultura y Religión. 1(1). pp. 108-125.

Martin, D. (2005). On Secularization: Toward a Revised General Theory. Burlington, Vt.: Ashgate.

Moniz, J. B. (2016). “A secularização na ultramodernidade católica europeia: uma proposta de análise contextual e multidimensional do fenômeno da secularização". Em Tese. 13(1). pp. 188-219.

Moniz, J. B. (2018). "Religiosity Index: A proposal for theorizing and measuring contemporary religious phenomena". Revista Brasileira de História das Religiões 1(32). pp. 191-219.

Norris, P. \& Inglehart, R. (2004). Sacred and Secular: Religion and Politics Worldwide. Cambridge: Cambridge University Press.

Ottaviano, G., Peri, G. (2006). "The economic value of cultural diversity: evidence from US cities". Journal of Economic Geography. 6(1). pp. 9-44.

Herring, S. C., \& Paolillo, J. C. (2006). Gender and genre variation in weblogs. Journal of Sociolinguistics, 10(4), 439-459.

Patsiurko, N., Campbell, J. L., Hall, J. A. (2012). "Measuring cultural diversity: ethnic, linguistic and religious fractionalization in the OECD". Ethnic and Racial Studies. 35(2). pp.195-217.

Pew Research Center (2014). "Global Religious Diversity Half of the Most Religiously Diverse Countries are in Asia-Pacific Region", visitado em 14 de junho de 2019 (http://www.pewforum.org/2014/04/04/global-religious-diversity/).

Revista Cultura \& Religión Vol. XIII, 2019 N² 2 (julio-diciembre)

Cómo citar este artículo: Botelho, J. (2019). "Diversidade cultural como secularização? Exame da correlação entre os índices de religiosidade e diversidade na Europa do século XXI”. Revista Cultura \& Religión.13(2). pp.75-102. 
Pickel, G. (2017). "Secularization - an empirically consolidated narrative in the face of an increasing influence of religion on politics". Politica \& Sociedade. 36(16). pp. 259294.

Pollack, Detlef. (2014). "Response by Detlef Pollack: Toward a new paradigm for the sociology of religion?". The Many Altars of Modernity: Toward a Paradigm for Religion in a Pluralist Age (pp. 111-122). Peter L. Berger (autor). Boston/Berlim: De Gruyter.

Pollack, Detlef \& Pickel, Gert. (2009). "Church-State relations and the vitality of religion in European comparison". Church and Religion in Contemporary Europe. Results from Empirical and Comparative Research (pp. 145-166). G. Pickel, O. Müller (editores). Wiesbaden: Springer-Verlag.

Taylor, C. (2007). A Secular Age. Cambridge: Harvard University Press.

Vilaça, H. (2006). Da Torre de Babel às Terras Prometidas - Pluralismo Religioso em Portugal. Porto: Edições Afrontamento.

Vilaça, H, et al. (2014). The Changing Soul of Europe Religions and Migrations in Northern and Southern Europe. Londres: Routledge.

Vilaça, H, Sell, C. E. \& Moniz, J. B. (2017). "A sociologia da religião hoje: secularização(ões), secularismo(s) ou laicidade?”. Política \& Sociedade. 16(36). pp. 7-19.

Voas, D., Crockett, A., Olson, D. (2002). "Religious pluralism and participation: Why previous research is wrong". American Sociological Review. 67(2). pp. 212-230.

Wohlrab-Sahr, M., Burchardt, M. (2017). "Revisitando o secular: secularidades múltiplas e trajetórias para a modernidade”. Política \& Sociedade. 16(36). pp. 143-173. 